\title{
Left Atrial Volume as A Parameter of The Ventricular Function in Patient with Non-Valvular Atrial Fibrillation
}

\author{
Mohamed A. E. Mostafa, Ensaf Bassam Yousef, Sherif Abd Alsalm Sakr, Ayman Elsayed Elbadrany* \\ Department of Cardiology, Faculty of Medicine, Mansoura University, Egypt. \\ *Corresponding author: Ayman Elsayed Elbadrany, Mobile: (+20) 01010668806, E-Mail: aymanalbdrany@yahoo.com
}

\begin{abstract}
Background: Remodeling of the left atrium (LA) is a reflection of chronicity of the underlying, often occult cardiovascular disease. The presence of left atrial enlargement indicates clinically significant risk of adverse cardiovascular consequences for the patient. Left atrial volume provides a more sensitive assessment of left atrial enlargement, which is an important predictor of AF, providing incremental information beyond that afforded by the clinical risk factors and conventional $\mathrm{M}$ mode LA dimension.

Objective: Assessment of left atrial volume as a parameter of ventricular function in patients with non-valvular atrial fibrillation.

Patients and methods: The study was conducted on convenient sample of 50 patients with non-valvular AF and 50 normal control group who presented to Damietta Cardiology Center Outpatient Echocardiography Laboratory for a resting transthoracic study. The eligible patients were adults aged from 26 to 67 years, who had no history of pacemaker implantation, valvular heart disease (except mild degree), congenital heart disease and ischemic or dilated cardiomyopathy.

Results: our study revealed that there was a strong direct significant graded relationship between the severity of diastolic dysfunction and left atrial volume index (LAVI) in patients of non-valvular AF. There was limited significance regarding Tei index and global longitudinal strain (GLS). Therefore, LAVI can be considered a sensitive and specific echocardiographic indicator for left ventricular diastolic dysfunction. We can consider LAVI the A1c of the heart.

Conclusion: Diastolic dysfunction in non-valvular AF patient can be assessed using LAVI with limited significance of Tei index and GLS. Regarding systolic function in those patients, it can be assessed using GLS as it is considered sensitive index of early systolic dysfunction.
\end{abstract}

Keywords: Left atrial volume index, GLS, Ventricular function, Non-valvular atrial fibrillation.

\section{INTRODUCTION}

LA is a reservoir for LV during systole and a conduit during early diastole and an active contractile chamber in late diastole. It contributes up to $30 \%$ of LV output during diastole. LA is directly exposed to LV pressure that increases with worsening of diastolic dysfunction. Consequently, LA wall pressure increases to maintain adequate $\mathrm{LV}$ filling. This results in increase LA wall tension and LA dilatation ${ }^{(\mathbf{1})}$.

$\mathrm{AF}$ is one of the most common tachyarrhythmia associated with adverse outcome. Many studies have shown a strong relationship between $\mathrm{AF}$ and diastolic dysfunction. Furthermore, the risk of heart failure progression is markedly increased once AF develops. Left atrial volume provides a more sensitive assessment of left atrial enlargement, which is an important predictor of $\mathrm{AF}$, providing incremental information beyond that afforded by the clinical risk factors and conventional M mode LA dimension ${ }^{(1)}$.

Aim of the present work was to assess left atrial volume as a parameter of ventricular function in patients with non-valvular atrial fibrillation.

\section{PATIENTS AND METHODS}

The study was conducted on convenient sample of 50 patients with non-valvular AF and 50 normal control group who presented to Damietta Cardiology Center Outpatient Echocardiography Laboratory for a resting transthoracic study. The eligible patients were adults aged from 26 to 67 years old, who had no history of pacemaker implantation, valvular heart disease (except mild degree), congenital heart disease and ischemic or dilated cardiomyopathy.

Inclusion criteria: Adult male or female presented with non-valvular AF.

Exclusion criteria: moderate to severe mitral stenosis or mitral valve replacement, ischemic or dilated cardiomyopathy, congenital heart disease, and history of pacemaker implantation.

\section{Ethical Approval:}

An approval of the study was obtained from Mansoura University academic and ethical committee. Every patient signed an informed written consent for acceptance of the operation.

All patients were subjected to the following:

1) Detailed history taking and clinical general and cardiac examination.

2) 12-leads electrocardiography (ECG).

3) Two-dimensional transthoracic echocardiography: The examination was performed by VIVID E 9, EKG leads using the 4D probe for all AF cases. Images were obtained from 
all the standard views. LV ejection fraction, fractional shortening, LVIDd, LVIDs, IVSd and IVSs with M-mode echo. Normal LV systolic function is identified when $\mathrm{EF}>55 \%$. Transmitral flow pattern at rest and during Valsalva maneuver, when necessary was used in order to analyze the diastolic function. PW Doppler was performed to measure peak velocity of $\mathrm{E}$ wave and deceleration time (DT) of mitral flow. The flow of Pulmonary vein could not be assessed in most of patients, so it was not used in diastolic function analysis. Tissue Doppler was used in order to measure velocity of the septal wall $\mathrm{e}^{\prime}$ wave at the level of the mitral valve annulus. All pulsed wave and tissue Doppler variable values were averaged by the mean measurement of five consecutive cardiac cycles. The ratio between peak velocity of the mitral $\mathrm{E}$ wave was assessed by pulsed wave Doppler and the (e') wave assessed by tissue Doppler was calculated and expressed as E/e' ratio.

M-mode is performed to measure the anteroposterior diameter of the left atrium. LAVI was measured by the mean left atrial volumes obtained by biplane modified Simpson method at apical 2 and apical 4 standard views. Then, tracing of left atrial area considering maximum atrial area before mitral opening and after ventricular systole represented on ECG at the end of $\mathrm{T}$ wave, and minimum atrial area after mitral valve closing and just before ventricular systole represented on ECG at $\mathrm{R}$ wave with exclusion tracing of left atrial appendage and pulmonary vein ${ }^{(2)}$. Then, LAVI was indexed by the body surface area that was estimated using Du Bois formula: $\mathrm{BSA}=0.007184 \times \mathrm{W}^{0.425} \times$ $\mathrm{H}^{0.725(3)}$. LAVI $\geq 34 \mathrm{ml} / \mathrm{m}^{2}$ was considered dilated (4).

One examiner who was blinded to clinical data performed all echocardiographic examinations.

\section{*Assessment of diastolic function.}

*Assessment of LA volume: By biplane modified Simpson (SIMP) method: (figure 1).
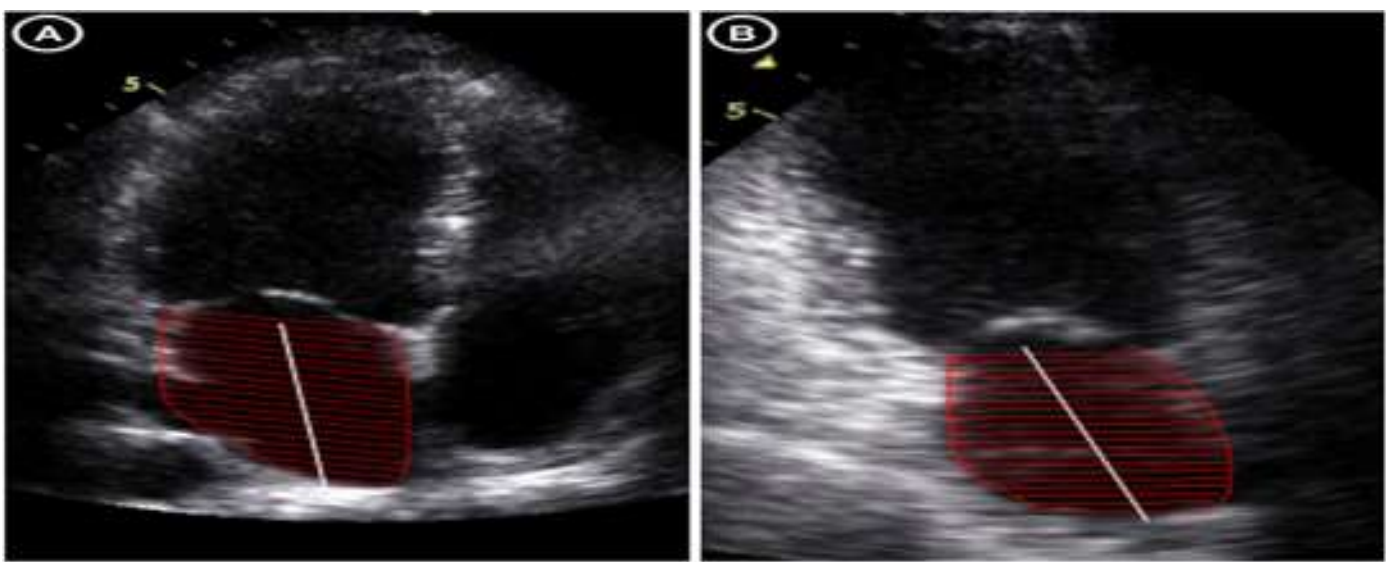

Figure (1): (A) and (B) Measurement of left atrial (LA) volume by the biplane Simpson method apical 2 and apical 4 views at ventricular end systole (maximum LA size): $\Pi / 4 \Sigma^{20}{ }_{i=1} a_{i} \times b_{i} \times L / 20$ where $a_{i}$ and $b_{i}=20$ disks obtained from orthogonal views.

*Assessment of global LV systolic function.

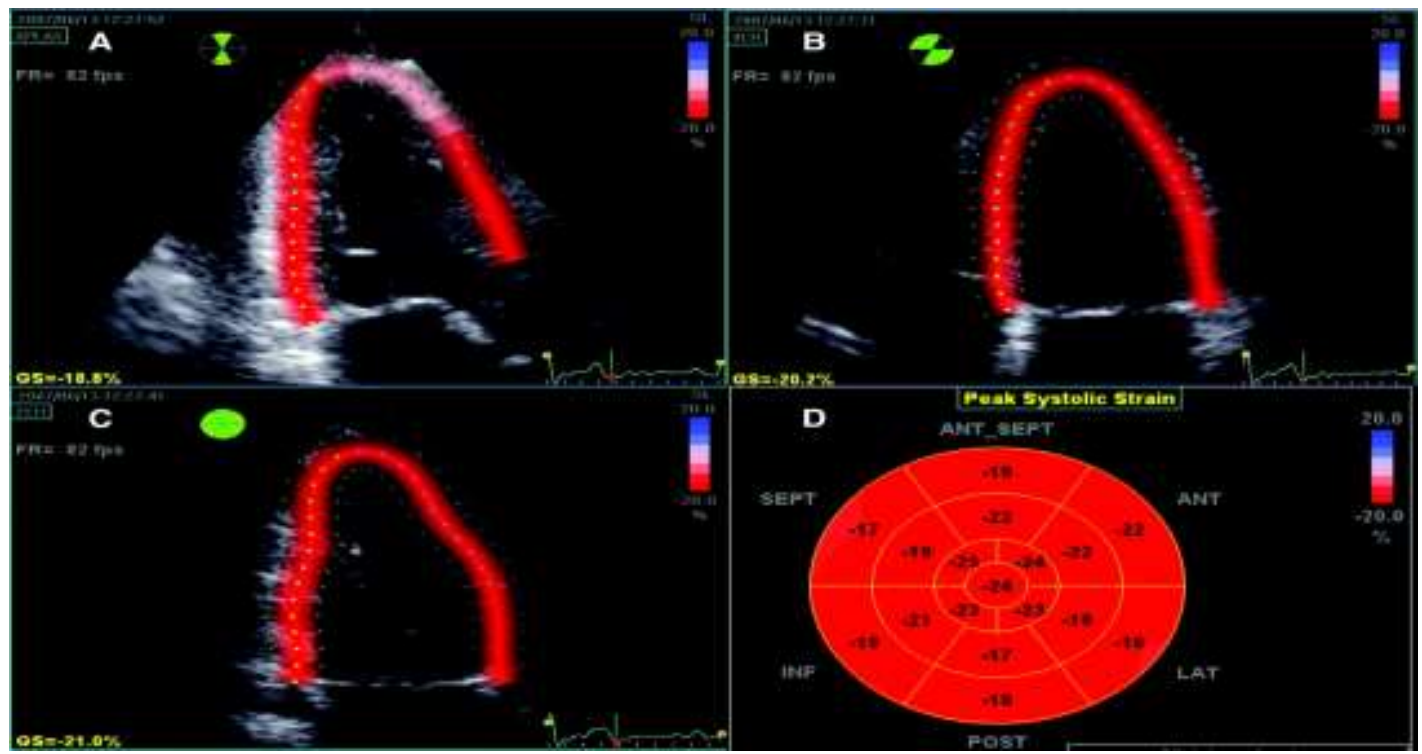

Figure (2): shows three standard views a) apical 3, b) apical 4 and c) apical 2 Speckle tracking to calculate average GLS represented at box D) bulls eye. 


\section{Measurement of myocardial performance index of the left ventricle:}

Tissue Doppler imaging was performed to calculate the Tei index, which combines systolic and diastolic time intervals of LV, by using the formula of $(\mathrm{a}-\mathrm{b}) / \mathrm{b}$, as (a) represents the duration between the closing and the opening of the mitral valve, and (b) represents the ejection time of LV (LVET). IVRT was calculated from the end of the S' wave to the onset of the $\mathrm{E}^{\prime}$ wave, and IVCT was measured from the end of the A' wave to the onset of the $\mathrm{S}^{\prime}$ wave.

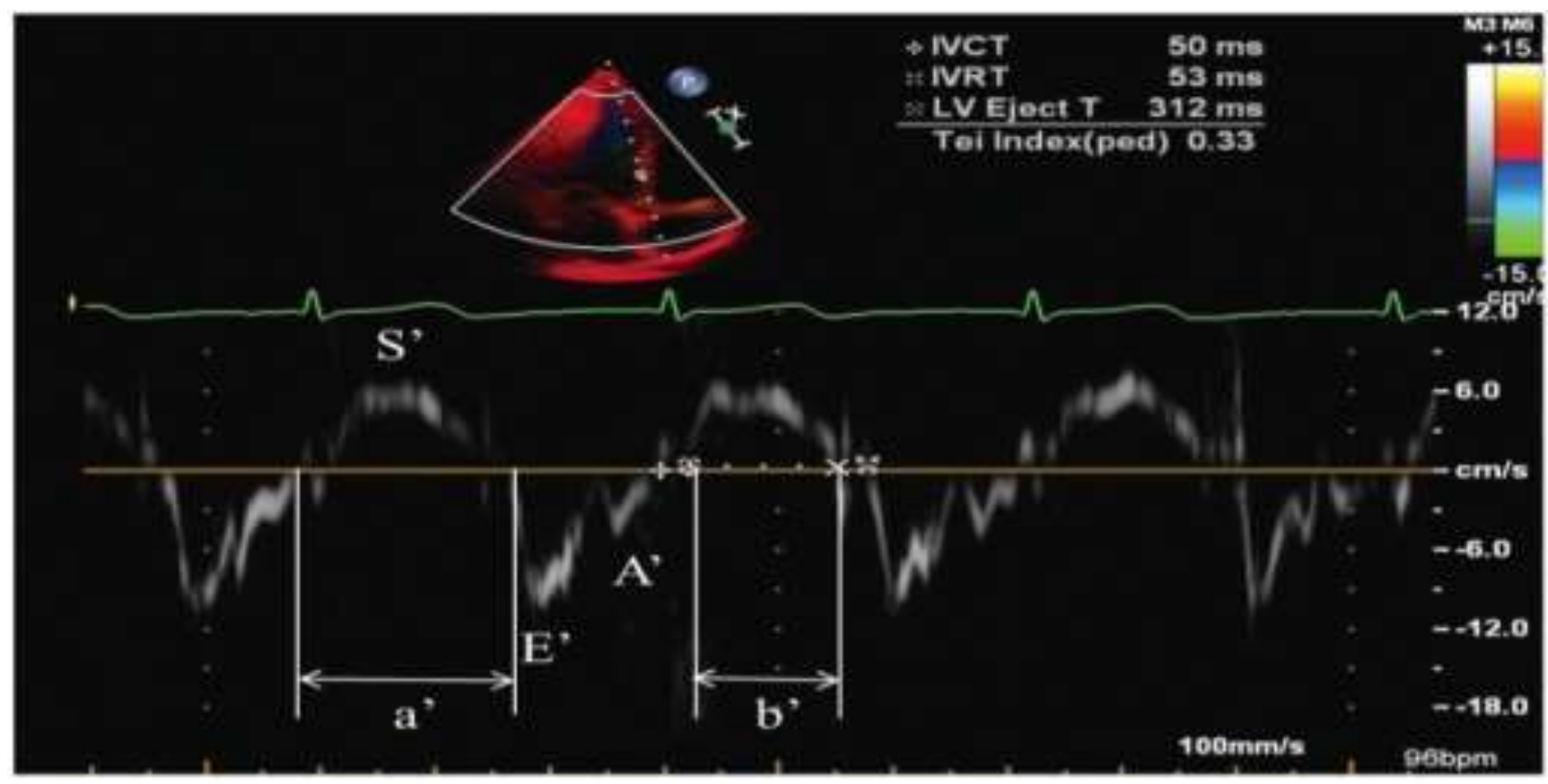

Figure (3): TDI for calculation Tei index. Tei index= $(\mathrm{a}-\mathrm{b}) / \mathrm{b}=(\mathrm{IVCT}+\mathrm{IVRT}) / \mathrm{ET}$. IVRT: isovolumetric relaxation time, IVCT: isovolumetric contraction time, ET: ejection time, LV Eject T: left ventricular ejection time, S': systolic myocardial velocity, A': late diastolic myocardial velocity, E': early diastolic myocardial velocity.

We made a comparative study between the normal control group (50 patients) and the AF group (50 patients) according to all the above parameters. Then, the correlation among the LAVI, Tei index and GLS in the AF groups and other parameter and their relation to the diastolic function were assessed.

\section{Statistical analysis}

The collected data were coded, processed and analyzed using the SPSS (Statistical Package for Social Sciences) version 22 for Windows ${ }^{\circledR}$ (IBM SPSS Inc, Chicago, IL, USA).

One-sample Kolmogorov-Smirnov test was first used to test the data normality. Number and percent were used to illustrate qualitative data and Chi-square test was used to test the association between categorical variables.

The mean \pm SD (standard deviation) represent continuous variables. Student $t$ test was used to compare the two groups, while Pearson correlation was used to correlate continuous data.

ROC curve was used to test specificity and sensitivity at different cutoff points. $P$ value $\leq 0.05$ was considered significant.

\section{RESULTS}

100 patients were included in the study, 50\% were normal sinus rhythm, which represent the control group and $50 \%$ were non valvular AF patients.

Table (1): Demographic data among the studied group

\begin{tabular}{|c|c|c|c|c|c|}
\hline \multirow[t]{2}{*}{ Variables } & \multicolumn{2}{|c|}{$\mathrm{AF}(\mathrm{n}=50)$} & \multicolumn{2}{|c|}{$\begin{array}{c}\begin{array}{c}\text { Control } \\
(\mathrm{n}=50)\end{array} \\
\end{array}$} & \multirow{2}{*}{$\begin{array}{c}\text { P- } \\
\text { value }\end{array}$} \\
\hline & No & $\%$ & No & $\%$ & \\
\hline \multicolumn{6}{|l|}{ Age/years } \\
\hline $\begin{array}{l}\text { Mean } \pm \\
\text { SD }\end{array}$ & \multicolumn{2}{|c|}{$\begin{array}{c}52.36 \pm \\
7.33 \\
\end{array}$} & \multicolumn{2}{|c|}{$49.82 \pm 6.5$} & \multirow[t]{2}{*}{0.07} \\
\hline Min-Max & \multicolumn{2}{|c|}{$37.00-67.00$} & \multicolumn{2}{|c|}{$28.00-64.00$} & \\
\hline \multicolumn{6}{|l|}{ Gender } \\
\hline Female & 27 & 54 & 33 & 66 & \multirow{2}{*}{0.221} \\
\hline Male & 23 & 46 & 17 & 34 & \\
\hline
\end{tabular}

t: student t-test, $\mathrm{X}^{2}$ : chi square test.

Table (2): Risk factor among the studied group

\begin{tabular}{||l|c|c|c|c|c|c||}
\hline \multirow{4}{*}{ Variables } & \multicolumn{2}{|c|}{$\begin{array}{c}\text { AF } \\
(\mathbf{n = 5 0})\end{array}$} & \multicolumn{2}{c|}{$\begin{array}{c}\text { Control } \\
(\mathbf{n}=\mathbf{5 0})\end{array}$} & \multirow{2}{*}{$\mathbf{X}^{\mathbf{2}}$} & \multirow{2}{*}{ P-value } \\
\cline { 2 - 5 } & $\mathbf{N o}$ & $\mathbf{\%}$ & $\mathbf{N o}$ & $\mathbf{\%}$ & & \\
\hline HTN & 34 & 68.0 & 14 & 28.0 & 16.02 & $<0.001^{* *}$ \\
\hline Smoking & 21 & 42.0 & 16 & 32.0 & 1.07 & 0.30 \\
\hline DM & 15 & 30.0 & 6 & 12.0 & 4.88 & $0.027^{*}$ \\
\hline IHD & 9 & 18.0 & 10 & 20.0 & 0.065 & 0.799 \\
\hline \hline
\end{tabular}

*significant $\mathrm{p}<0.05, * *$ highly significant $\mathrm{p}<0.001$

No significant differences regarding age and gender in non-valvular AF group with predominance of females over males. Highly significant prevalence of 
hypertension among non-valvular AF group as well as significant prevalence of diabetes mellitus among nonvalvular AF group, No significant prevalence of smoking or ischemic heart disease (Tables $1 \& 2$ ).

Table (3): Echocardiographic data among the studied group

\begin{tabular}{|c|c|c|c|c|}
\hline Variables & $\begin{array}{c}\mathbf{A F} \\
(\mathbf{n}=50)\end{array}$ & $\begin{array}{c}\text { Control } \\
(\mathrm{n}=50)\end{array}$ & t-test & P-value \\
\hline Ao.d (cm) & $\begin{array}{c}2.72 \pm \\
0.16\end{array}$ & $\begin{array}{c}2.84 \pm \\
0.21\end{array}$ & 3.24 & $0.002 *$ \\
\hline La.d (cm) & $\begin{array}{c}3.82 \pm \\
0.24\end{array}$ & $\begin{array}{c}3.62 \pm \\
0.22\end{array}$ & 4.11 & $<0.001 * *$ \\
\hline $\begin{array}{l}\text { LVIDd } \\
(\mathrm{cm})\end{array}$ & $\begin{array}{c}5.12 \pm \\
0.30\end{array}$ & $\begin{array}{c}5.13 \pm \\
0.40\end{array}$ & 0 & 1 \\
\hline $\begin{array}{l}\text { LVIDs } \\
\text { (cm) }\end{array}$ & $\begin{array}{c}3.70 \pm \\
0.24\end{array}$ & $\begin{array}{c}3.68 \pm \\
0.21\end{array}$ & 3.9 & 0.97 \\
\hline ISd (cm) & $\begin{array}{c}1.00 \pm \\
0.20\end{array}$ & $\begin{array}{c}0.85 \pm \\
0.13\end{array}$ & 3.2 & $0.002 *$ \\
\hline \begin{tabular}{|l|} 
LVPWd \\
$(\mathrm{cm})$
\end{tabular} & $\begin{array}{c}1.00 \pm \\
0.30\end{array}$ & $\begin{array}{c}0.90 \pm \\
0.10\end{array}$ & 3.1 & $0.002 *$ \\
\hline FS\% & $\begin{array}{c}32.5 \pm \\
2.8\end{array}$ & $\begin{array}{c}33.24 \pm \\
2.53 \\
\end{array}$ & 3.2 & $0.003^{*}$ \\
\hline EF\% & $\begin{array}{c}60.6 \pm \\
3.7\end{array}$ & $\begin{array}{c}62.36 \pm \\
3.84\end{array}$ & 3.3 & $0.003^{*}$ \\
\hline $\mathbf{E}(\mathbf{m} / \mathbf{s})$ & $\begin{array}{c}0.61 \pm \\
0.22\end{array}$ & $\begin{array}{c}0.76 \pm \\
0.14\end{array}$ & 4.13 & $<0.001 * *$ \\
\hline \begin{tabular}{|l|} 
Septal \\
$\mathrm{e}^{\prime}(\mathrm{m} / \mathrm{sec})$
\end{tabular} & $\begin{array}{c}0.06 \pm \\
0.01 \\
\end{array}$ & $\begin{array}{c}0.12 \pm \\
0.01 \\
\end{array}$ & 17.42 & $<0.001 * *$ \\
\hline$E / e^{\prime}$ & $\begin{array}{r}10.23 \\
\pm 3.51\end{array}$ & $\begin{array}{c}6.11 \pm \\
0.97\end{array}$ & 7.97 & $<0.001 * *$ \\
\hline $\begin{array}{l}\text { DT.(ms) } \\
\end{array}$ & $\begin{array}{c}192 \pm \\
22.1\end{array}$ & $\begin{array}{c}160 \pm \\
14.3\end{array}$ & 8.70 & $<0.001 * *$ \\
\hline Tei & $\begin{array}{c}0.62 \pm \\
0.10 \\
\end{array}$ & $\begin{array}{c}0.40 \pm \\
0.05\end{array}$ & 13.23 & $<0.001 * *$ \\
\hline GLS & $\begin{array}{l}-12.29 \\
\pm 4.51\end{array}$ & $\begin{array}{l}-18.01 \\
\pm 0.99\end{array}$ & 46.38 & $<0.001 * *$ \\
\hline $\begin{array}{l}\text { LA vol. } \\
\text { index } \\
\left(\mathbf{m l} / \mathbf{m}^{2}\right)\end{array}$ & $\begin{array}{c}34.48 \\
\pm 6.42\end{array}$ & $\begin{array}{c}21.43 \pm \\
3.93\end{array}$ & 16.79 & $<0.001 * *$ \\
\hline
\end{tabular}

Comparing non-valvular AF group with normal group (table 3). In the non-valvular AF group, there was highly significant increase $(\mathrm{p}<0.001)$ in the following echo-parameter: La.D: left atrial diameter, E/e' ratio between E and e' waves, DT: E wave deceleration time, Tei index: myocardial performance index and LAVI: left atrial volume index.

In addition, there was significant increase ( $p$ 0.002) in AOD: aortic root diameter and there was positive correlation with concentric LVH represented by ISD: interventricular septal diameter and LVPWD: left ventricular posterior wall diameter. While, there was highly significant decrease $(p<0.001)$ in E: Mitral flow protodiastolic velocity, e': Septal mitral annulus protodiastolic and GLS: global longitudinal strain.
Table (4): Diastolic dysfunction among AF group

\begin{tabular}{|l|c|c|}
\hline \multirow{2}{*}{$\begin{array}{l}\text { Diastolic } \\
\text { dysfunction }\end{array}$} & \multicolumn{2}{|c|}{ AF $(\mathbf{N}=\mathbf{5 0})$} \\
\cline { 2 - 3 } Grade 1 & $\mathbf{N}$ & \% \\
\hline Grade 2 & 22 & 56 \\
\hline
\end{tabular}

The AF group has diastolic dysfunction (DD), distributed as: grade $\mathrm{I}=56 \%$ and grade $\mathrm{II}=44 \%$.

Table (5): Correlation among LA vol. index and other parameters

\begin{tabular}{||l|c|c||}
\hline \multirow{2}{*}{ Variables } & \multicolumn{2}{|c||}{ LA vol. index $\left(\mathbf{m l} / \mathbf{m}^{\mathbf{2}}\right)$} \\
\cline { 2 - 3 } & $\mathbf{r}$ & $\mathbf{p}$ \\
\hline Ao. $(\mathbf{c m})$ & -0.022 & 0.878 \\
\hline Lad $(\mathbf{c m})$ & 0.295 & $0.038^{*}$ \\
\hline E $(\mathbf{m} / \mathbf{s})$ & 0.333 & $0.018^{*}$ \\
\hline Septal e' (m/sec) & -0.350 & $0.013^{*}$ \\
\hline E/e' & 0.636 & $<0.001^{* *}$ \\
\hline DT. $(\mathbf{m s})$ & -0.155 & 0.283 \\
\hline Tei & 0.077 & 0.595 \\
\hline GLS & 0.003 & 0.985 \\
\hline
\end{tabular}

Table (5) provided clear data of highly positive significant correlation between LAVI and E/e' ( $p$ < 0.001 ) and positive significant correlation between LAVI and E (Mitral flow protodiastolic velocity) and LAD (left atrial diameter) $(\mathrm{p}=0.018$ and 0.038 respectively). But, there was inverse significant correlation between LAVI and septal e'(Septal mitral annulus protodiastolic) $(\mathrm{p}=0.013)$. Also, we noticed that there was no significant correlation between LAVI and other parameter.

Table (6): Correlation among Tei index and other parameters

\begin{tabular}{||c|c|c||}
\hline \multirow{2}{*}{ Variables } & \multicolumn{2}{|c|}{ Tei index } \\
\cline { 2 - 3 } & $\mathbf{r}$ & $\mathbf{p}$ \\
\hline Ao. $(\mathbf{c m})$ & -0.014 & 0.926 \\
\hline La. $(\mathbf{c m})$ & -0.017 & 0.904 \\
\hline E $(\mathbf{m} / \mathbf{s})$ & -0.163 & 0.258 \\
\hline $\begin{array}{l}\text { Septal e' } \\
\text { (m/sec) }\end{array}$ & -0.104 & 0.471 \\
\hline E/e' & -0.042 & 0.772 \\
\hline DT. $(\mathbf{m s})$ & -0.023 & 0.872 \\
\hline GLS & 0.017 & 0.907 \\
\hline LVIDd & 0.035 & 0.807 \\
\hline LVIDs & 0.099 & 0.492 \\
\hline LVISd & 0.070 & 0.625 \\
\hline LVPWd & 0.139 & 0.333 \\
\hline EF & -0.193 & 0.491 \\
\hline LAVI & 0.085 & 0.554 \\
\hline
\end{tabular}

Table (6) showed the correlation among Tei index and other parameters in non-valvular AF group where there was no significant correlation regarding Tei index (myocardial performance index) and other echocardiographic parameters taking in consideration 
that there was negative correlation among Tei index and diastolic function parameters represented by LAD (left atrial diameter, E (Mitral flow protodiastolic velocity), septal e' (Septal mitral annulus protodiastolic), E/e', and systolic function indicators represented by EF and GLS.

Table (7): Correlation among GLS and other parameters

\begin{tabular}{||l|c|c||}
\hline \multirow{2}{*}{ Variables } & \multicolumn{2}{|c|}{ GLS } \\
\cline { 2 - 3 } & $\mathbf{r}$ & $\mathbf{p}$ \\
\hline Ao. $(\mathbf{c m})$ & -0.009 & 0.948 \\
\hline La. $(\mathbf{c m})$ & -0.082 & 0.572 \\
\hline E $(\mathbf{m} / \mathbf{s})$ & 0.022 & 0.878 \\
\hline Septal e' (m/sec) & 0.107 & 0.458 \\
\hline E/e' & -0.086 & 0.552 \\
\hline DT. (ms) & -0.024 & 0.871 \\
\hline
\end{tabular}

Correlation among GLS and other parameters showed that there was non-significant inverse correlation among GLS with E/e' and mitral deceleration time DT (Table 7).

Table (8): Roc curve for prediction of grade1and grade 2 diastolic dysfunction by LA vol. index in non valvular AF patients

\begin{tabular}{|c|c|c|c|c|c|c|c|c|}
\hline & AUC & $\begin{array}{c}\text { 95\% } \\
\text { CI }\end{array}$ & $\begin{array}{c}\text { Cut } \\
\text { off }\end{array}$ & SN & SP & PPV & NPV & Accuracy \\
\hline Grade 1 & 0.90 & $(0.83-0.97)$ & $>22.65$ & $\begin{array}{c}89.3 \\
\%\end{array}$ & $\begin{array}{c}80 \\
\%\end{array}$ & $\begin{array}{c}71.4 \\
\%\end{array}$ & $\begin{array}{c}93 \\
\%\end{array}$ & $\begin{array}{c}83.3 \\
\%\end{array}$ \\
\hline Grade 2 & 0.961 & $(0.91-1)$ & $>22.65$ & $\begin{array}{c}95.5 \\
\%\end{array}$ & $\begin{array}{c}84 \\
\%\end{array}$ & $\begin{array}{c}72 \\
\%\end{array}$ & $\begin{array}{c}97.5 \\
\%\end{array}$ & $\begin{array}{c}87.5 \\
\%\end{array}$ \\
\hline
\end{tabular}

Table (8) showed high sensitivity and specificity of LAVI for grade I and II diastolic dysfunction in patients with non-valvular AF, sensitivity and specificity $89.3 \%$ and $80 \%$ respectively. For grade I, DD for LAVI = $31.51 \pm 4.55 \mathrm{~mL} / \mathrm{m}^{2}(\mathrm{AUC}=0.90)$ and for grade II, DD there was $95.5 \%$ sensitivity and $84 \%$ specificity and $\mathrm{LAVI}=38.26 \pm 6.55 \mathrm{~mL} / \mathrm{m}^{2}(\mathrm{AUC}=0.961)$.

\section{DISCUSSION}

This study was performed to illustrate the advanced elevation in volume of left atrium with aggravation of the grade of diastolic dysfunction in adults with ejection fraction preserved to some extent. Our main finding was to demonstrate the direct influence of DD on left atrial remodeling. These results strengthen the concept of the prognostic role of left atrial dilation as a marker of cardiovascular event in patients with atrial fibrillation.

On the global 100 patient set, $50 \%$ were normal sinus rhythm, which represented the control group and there was no wide variation in age group between normal and AF group (49.82 \pm 6.5 and $52.36 \pm 7.33$ years respectively). Males represent $66 \%$ and females represent 34\%, 28\% were HTN: $32 \%$ smokers, $12 \%$ DM and 20\% IHD. The other group (non valvular AF) showed mean age of $52.36 \pm 7.33$ years. Males represented $54 \%$ and $68 \%$ were HTN: $42 \%$ were smokers, $30 \%$ were DM and 18\% IHD. All of the patients had preserved LV systolic function with mean ejection fraction of $62.36 \pm 3.84 \%$. All the patients of the AF group had diastolic dysfunction, distributed as: grade $\mathrm{I}=56 \%$ and grade $\mathrm{II}=44 \%$.

In the present study, LAVI average estimation in patients with normal diastolic function was $20.13 \pm$ $2.0 \mathrm{~mL} / \mathrm{m}^{2}$. This value was very close to that found in normal adults, which showed values between $20.13 \pm 2$ and $21 \pm 7 \mathrm{~mL} / \mathrm{m}^{2(2)}$.

By comparing our study demographic data with Tsang et al. ${ }^{(1)}$ study which was done on 840 patients (39\% men with mean age of $75 \pm 7$ years), and Lee et al. (4) study which compared 137 patients with persistent $\mathrm{AF}$ and left ventricular ejection fraction (LVEF) above $50 \%$ and 137 non-AF patients (41\% female with mean age of $67 \pm 9$ years). Our study showed that there was no significant differences regarding age and gender between the AF group and normal control group. This is in agreement with Tsang $\boldsymbol{e t}$ al. ${ }^{(\mathbf{1})}$ study and Lee $\boldsymbol{e t}$ al. (4) study but in our study there was predominance of female in AF group as in Tsang et $_{\text {al }}{ }^{(1)}$ study and not found in Lee et al. ${ }^{(4)}$ study.

As regards the clinical characteristics of the sample of our study, there was significant prevalence of hypertension and DM in the AF group compared to the normal control group and there was no significant prevalence regarding ischemic heart disease and smoking. By comparing our clinical data with Tsang $\boldsymbol{e t}$ al. ${ }^{(1)}$ study, they revealed that there was significant prevalence of myocardial infarction and congestive heart failure in non-valvular AF group, which were excluded in selection of cases in our study. However, there was non-significant prevalence of diabetes in $\mathrm{AF}$ group which had significant prevalence in AF group of our study. Our study matches with Tsang et al. ${ }^{(1)}$ study in prevalence of hypertension as there is significant prevalence in non-valvular AF group in both studies, and there was no significant prevalence of smoking in $\mathrm{AF}$ group similarly as our study. However, Lee et al. ${ }^{(4)}$ reported that there is no significant difference between non-AF patients and AF patients regarding hypertension and DM.

Regarding to echocardiographic data, our study showed that in non-valvular AF group there was significant increase in the following echocardiographic parameter: Aortic root diameter, left atrial diameter, E/e' ratio, deceleration time (DT), Tei index and LAVI, while there was highly significant decrease in E, e', and more impaired global longitudinal strain. Tsang et al. ${ }^{(\mathbf{1})}$ showed that there was significant increase in the LAVI and significant decrease in left ventricular EF and FS in non-valvular AF group which is similar to our result. Tsang et al. ${ }^{(1)}$ study showed significant increase in LVIDd and LVPWD that is not matched with our result. Tsang et al. ${ }^{(1)}$ study showed no significant difference between the two groups regarding E and mitral DT, which were significant in our study. This may be because all cases of the non-valvular AF group in our 
study had diastolic dysfunction. Also, Tsang et al. (1) did not compare between the two groups regarding tissue Doppler assessment, Tei index and global longitudinal strain that are included in our assessment. Lee et al. ${ }^{(4)}$ showed significant increase in LAVI in AF group as our study. Lee et al. (4) study showed significant impairment of GLS in AF group as shown in our study in spite of normal left ventricular ejection fraction. So, our study revealed that AF may impair GLS that is more sensitive measure of early systolic dysfunction and predictor for cardiovascular outcome.

In regard to Tei index, our study showed that Tei index showed highly significant increase in nonvalvular AF group compared to normal group as the entire group had diastolic dysfunction and there was no significant relation as regards the grade of diastolic dysfunction. However, in Cacciapuoti et al. ${ }^{(5)}$ study that was done on 62 hypertensive Italian patients to compare between Tei index and LAVI as indicators for diastolic dysfunction, it declared that there was significant increase in Tei and LAVI in grade II over grade I. All patients of this study were hypertensive.

In Shingu et al. ${ }^{(6)}$ study, MPI is not a reliable parameter for the assessment of contractile function in pressure-overload heart failure. It is normal in diastolic dysfunction with or without preserved ejection fraction but this study was on rats. Also, Sud and Massel (7) study examining MPI in different degrees of aortic valve stenosis in human. They reported that MPI was normal in patients with severe aortic valve stenosis and LVEF was $40 \%$. They already showed the limitation of this index as a parameter of diastolic or systolic function.

In our study, when we correlated Tei index with other parameter in non-valvular AF group, there was negative and non-significant correlation among Tei index and diastolic function parameters represented by LAD, E, septal e', E/e', and systolic function indicators reprented by EF and GLS.

In regard to GLS, our study showed highly significant decrease in GLS in AF group than in normal group and there was no significant relation as regards the grade of diastolic dysfunction. Also, Lee et al. (4) study supported our result as it showed more impairment in GLS and a larger left atrial volume index in AF patients as shown in our study. In our study, by correlation of GLS to other parameters, there was inverse but not significant correlation among GLS and e', Tei index and LAVI (measured by biplane modified Simpson). This matches with Lee et al. (4) study, regarding LAVI (measured by biplane modified Simpson). But, there was inverse significant correlation with e' taking in consideration that all AF patients of Lee study were persistent AF.

Regarding LAVI, LAV was measured by biplane modified Simpson method then indexed to BSA. Our study showed highly positive significant correlation between LAVI and E/e' and positive significant correlation between LAVI and E wave and
LAD. But, there was inverse significant correlation between LAVI and septal e' and there was no significant correlation between LAVI and other parameter. Also, it is clear that there was highly significant increase in LAVI in grade II over grade I as LAVI has direct relation with grade of diastolic dysfunction as LAVI = $31.51 \pm 4.55 \mathrm{~mL} / \mathrm{m}^{2}$ for grade $\mathrm{I}$, and LAVI $=38.26 \pm$ $6.55 \mathrm{~mL} / \mathrm{m}^{2}$ for grade II diastolic dysfunction.

In our study, as well as El Aouar et al. ${ }^{(8)}$ that was conducted on 500 Brazilian patients, Pritchett et al. study, which was performed on 2042 American patients over 45 years, and Tsang et al. ${ }^{(1)}$ study, LAVI exhibited good specificity and sensitivity in detection of diastolic dysfunction.

Concerning LAVI ROC curve analysis, El Aouar et al. ${ }^{(8)}$ observed that there was a progressive increase in LAVI strength for identification of diastolic dysfunction. For diastolic dysfunction grade I, we noticed 74.6 specificity and $60.45 \%$ sensitivity for $\mathrm{LAVI}=24 \mathrm{~mL} / \mathrm{m}^{2}$. The curve was perfect for detection of grade II DD $(\mathrm{AUC}=0.970)$ with $\mathrm{LAVI} \geq 27.9 \mathrm{~mL} / \mathrm{m}^{2}$ was $98 \%$ sensitive and $90.6 \%$ specific. For grade III DD, LAVI $\geq 40 \mathrm{~mL} / \mathrm{m}^{2}$ showed $100 \%$ sensitivity and specificity. However, in our study LAVI ROC curve analysis showed high sensitivity and specificity of LAVI for grade I and II diastolic dysfunction in patients with non-valvular AF, sensitivity and specificity $89.3 \%$ and $80 \%$ respectively for grade $\mathrm{I}$ DD for LAVI = $31.51 \pm 4.55 \mathrm{~mL} / \mathrm{m}^{2}$ (AUC $\left.=0.90\right)$. For grade II DD there was $95.5 \%$ sensitivity and $84 \%$ specifity, LAVI $38.26 \pm$ $6.55 \mathrm{~mL} / \mathrm{m}^{2}(\mathrm{AUC}=0.961)$. The data from the El Aouar et al. ${ }^{(8)}$ study might not be applied on atrial fibrillation patients, because it was performed only in patients with normal sinus rhythm. In Pritchett et al. ${ }^{(9)}$ study, the LAVI increased with worsening of diastolic dysfunction: $23 \pm 6 \mathrm{ml} / \mathrm{m}^{2}$ (normal), $25 \pm 8 \mathrm{ml} / \mathrm{m}^{2}$ (grade I diastolic dysfunction), $31 \pm 8 \mathrm{ml} / \mathrm{m}^{2}$ (grade II diastolic dysfunction) and $48 \pm 12 \mathrm{ml} / \mathrm{m}^{2}$ (grades III to IV diastolic dysfunction). There was inverse association between LAVI and EF. In our study there was also increase in LAVI with worsening of DD although our values were higher: $31.51 \pm 4.55 \mathrm{ml} / \mathrm{m}^{2}$ (grade I DD) and $40.08 \pm 3.99$ (grade II DD). This difference may be due to selection of cases. Our study showed highly significant association between AF and LAVI: $20.13 \pm$ $2.00 \mathrm{ml} / \mathrm{m}^{2}$ (normal), $35.28 \pm 6.05 \mathrm{ml} / \mathrm{m}^{2}$.

The discrepancy between the values of LAVI related to grade of diastolic dysfunction may be due to racial issue, the selection of cases as we selected non valvular AF patients with no moderate to severe mitral regurge and without ischemic or dilated cardiomyopathy, and the method of measurement of LAVI. As there are three method of measurement and there is significant differences exist among these 3 commonly used methods for measuring LA volume as illustrated in the Jiamsripong et al. (10) study that showed significant variation in the value of the measurement of LA volume by 3 commonly used techniques. The prolate ellipse method (PE); that 
routinely yields smaller values compared to either the AL area-length method or SIMP Simpson method. We used biplane Simpson method.

Our study also compare between grade I and grade II diastolic dysfunction in non-valvular AF group. According to echocardiographic data, our study as well as the El Aouar et al. ${ }^{(\mathbf{8})}$ showed significant relationship among E wave, septal e', E/e' ratio and DT in the grade $\mathrm{I} \mathrm{DD}$ in the $\mathrm{AF}$ group compared to the control group. When we turn onto comparison between grade II DD in the AF group and the control group in our study, we noticed that there was significant increase in DT in AF group of grade II DD but not significant in El Aouar et al. ${ }^{(8)}$.

In our study there was significant decrease in septal $e^{\prime}$ and significant increase in mitral E/e' ratio in AF group of grade II DD compared to normal group, similar to El Aouar et al. ${ }^{\left({ }^{(8)}\right.}$. There was no significant increase regarding mitral $\mathrm{E}$ wave in both studies. This is due to progressive deterioration of diastolic function grade II leading to increase LV pressure and disproportional increase in LA pressure thus blood pushed down to the LV with higher velocity termed as pseudo-normal $\mathrm{E}$ wave, which is unmasked by valsalva maneuver that increase venous return to $\mathrm{LV}$. The diseased LV will not accommodate the increase in venous return in early filling phase that is reflected as small E wave.

In El Aouar et al. ${ }^{(8)}$ study there was another group of grade III DD that was not included in our study this may be due to less number of patients in our study and that the included patients are only with less severe heart diseases of the outpatient clinic, so less prevalence of severe diastolic dysfunction is counted which is a restriction of our study. However, it shows the natural appearance of milder diastolic dysfunction in the absence of considerable systolic dysfunction, as observed in our everyday practice.

In regard to LAVI our study showed that there was highly significant increase in non-valvular $\mathrm{AF}$ group including both grade I and grade II DD. Also, there was highly significant increase in LAVI in grade II DD compared to grade I similar to El Aouar et al. ${ }^{\left({ }^{(8)} \text {. }\right.}$

\section{CONCLUSION}

Diastolic dysfunction in non valvular $\mathrm{AF}$ patient can be assessed using LAVI with limited significance of Tei index and GLS. Regarding systolic function in those patients, it can be assessed using GLS as it is considered sensitive index of early systolic dysfunction. Our study revealed that there was strong direct significant graded relationship between the severity of diastolic dysfunction and LAVI in patients of non-valvular AF and there was limited significance regarding Tei index and GLS. LAVI can be considered a sensitive and specific echocardiographic indicator for left ventricular diastolic dysfunction, we can consider LAVI the A1c of the heart.

It is clear that patients with non-valvular AF have significant impairments of GLS despite good left ventricular systolic function estimated by M-mode EF. So, AF can be considered an incipient factor that can impair systolic function of the heart as GLS is more sensitive measure of early systolic dysfunction and predictor for cardiovascular outcome.

\section{REFERENCES}

1. Tsang T, Barnes M, Gersh B et al. (2002): Left atrial volume as a morphophysiologic expression of left ventricular diastolic dysfunction and relation to cardiovascular risk burden. Am J Cardiol., 90 (12): 1284-1289.

2. Ujino K, Barnes M, Cha S et al. (2006): Twodimensional echocardiographic methods for assessment of left atrial volume. Am J Cardiol., 98: 1185-1188.

3. DuBois D, Du Bois E (1989): A formula to estimate the approximate surface area if height and weight be known 1916. Nutrition, 5: 303-11.

4. Lee A, See V, Lim T et al. (2016): Atrial fibrillation ablation by single ring isolation versus wide antral isolation: Effects on left atrial size and function. Int $\mathbf{J}$ Cardiol., 206: 1-6.

5. Cacciapuoti V, Scognamiglio A, Delli Paoli V et al. (2012): Left Atrial Volume Index as Indicator of Left Ventricular Diastolic Dysfunction: Comparation between Left Atrial Volume Index and Tissue Myocardial Performance Index. Journal of Cardiovascular Ultrasound, 20 (1): 25-29.

6. Shingu Y, Amorim P, Nguyen $T$ et al. (2010): Myocardial performance (Tei) index is normal in diastolic and systolic heart failure induced by pressure overload in rats. European Journal of Echocardiography, 11 (10): 829-833.

7. Sud S, Massel D (2009): An echocardiographic study of the limitations of the Tei index in aortic stenosis. Echocardiography, 26: 891-9.

8. El Aouar A, Meyerfreud D, Magalhães $P$ et al. (2013): Relationship Between Left Atrial Volume and Diastolic Dysfunction in 500 Brazilian Patients. Arq Bras Cardiol., 101 (1): 52-58.

9. Pritchett A, Jacobsen S, Mahoney D et al. (2003): left atrial volume as an index of left atrial size, a population based study, J AM Coll cardiology, 41: 1036-1043

10. Jiamsripong $P$, Honda $T$, Reuss $C$ et al. (2008): Three methods for evaluation of left atrial volume. Eur J Echocardiogr., 9: 351-355. 